\title{
Rigid-plate fixation for the treatment of sternal nonunion
}

\author{
Liza C. Wu, MD, ${ }^{a}$ John Renucci, MD, ${ }^{\text {b }}$ and David H. Song, MD, FACS, \\ Chicago, III, and Grand Rapids, Mich
}

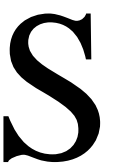

terile sternal nonunion is defined as a persistent fracture of the sternum after 3 months without signs of healing. It is a morbid condition characterized by sternal instability, pain, and the absence of infection. In addition to being a crippling condition, one can assume that sternal instability can lead to more serious conditions.

Two causes for sternal nonunion have been described: it can be the result of cardiac surgical intervention or trauma. Regardless of the cause, only a few studies have addressed the entity of sterile sternal nonunion and its treatment. ${ }^{1-5}$ We present 6 cases of sterile sternal nonunion, including its presentation, treatment with open reduction and rigid-plate fixation with the Sternalock system (W. Lorenz Surgical, Inc, Jacksonville, Fla), and the outcomes.

\section{Patients and Methods}

From October 2002 through October 2003, 6 patients were given diagnoses of sterile sternal nonunion at 2 institutions. The 4 median sternotomies were previously closed with parasternal cerclage wires, 1 trauma patient underwent transternal wiring of the sternum, and another trauma patient had no prior attempt at fixation. Table 1 lists the patient demographics, causes, and time of presentation.

Open reduction and internal fixation of the sternum was performed at 2 institutions by 2 surgeons using the same technique. A preoperative chest radiograph is helpful, although not necessary. The sternum is exposed, and all wires are removed. The fracture lines are identified, and the overlying fibrous tissue is cleared from the sternum (Figure 1). The pseudoarthrosis joining the sternal edges is debrided to healthy bone. All longitudinal and transverse fractures are identified and reduced, and static compression is applied. The periosteum is minimally dissected off the anterior sternum to allow the titanium plates to lie flush to the sternum. Specially designed titanium Sternalock plates are used to span all fracture lines (Figure 2).

\footnotetext{
From the Section of Plastic and Reconstructive Surgery, ${ }^{a}$ University of Chicago Hospitals, Chicago, Ill, and Plastic Surgery Associates, PC, ${ }^{\mathrm{b}}$ Grand Rapids, Mich.

Received for publication Feb 10, 2004; accepted for publication Feb 23, 2004.

Address for reprints: David H. Song, MD, FACS, University of Chicago Hospitals, Section of Plastic and Reconstructive Surgery, 5841 S Maryland Ave, MC 6035, Chicago, IL 60637 (E-mail: dsong@ surgery.bsd. uchicago.edu).

J Thorac Cardiovasc Surg 2004;128:623-4

$0022-5223 / \$ 30.00$

Copyright $\odot 2004$ by The American Association for Thoracic Surgery

doi:10.1016/j.jtcvs.2004.02.016
}

\section{Results}

Follow-up was 6 to 18 months. All 6 patients had their fractures identified and underwent rigid-plate fixation of their fractures. There were no complications. All patients became pain free and had no sternal instability postoperatively. There were no cases of sternal infection. Bony healing was demonstrated in follow-up radiographs.

\section{Discussion}

Nonunion of a fracture is defined as the cessation of both the periosteal and endosteal healing responses after 3 months. The fracture shows no visibly progressive signs of healing, and there is a gap between the fragment ends and motion between the fragments.

Patients with sternal nonunion have sternal instability, pain, and no signs of infection. The history is significant for either median sternotomy for cardiothoracic intervention or sternal fracture after trauma. The incidence of sternal nonunion remains less than $1 \%$ after median sternotomy and is encountered even less often after trauma, yet it remains an entity that is rarely addressed.

The pathogenesis of sternal nonunion is dependent on what the authors have designated as extrinsic and intrinsic risk factors. Extrinsic risk factors include any environmental or systemic effects on healing. Environmental factors include both operative and postoperative events, such as bilateral internal thoracic artery harvest, prolonged pump time, prolonged ventilatory dependence, and low cardiac output. Recognized systemic factors of sternal nonunion include but are not limited to the use of steroids, poor nutritional status, chronic obstructive pulmonary disease, and diabetes.

Intrinsic factors are characteristics of the fracture and bone that contribute to the likelihood of sternal nonunion. This includes technical errors in sternotomy, osteoporitic bone, multiple longitudinal and transverse fracture lines, fracture gap, decreased vascularity of the bony segments, and instability. The pathogenesis of sternal nonunion in any patient is multifactorial.

Because sternal nonunion is a rare complication, there is no consensus on how to treat these patients. A few methods have been developed over the years that involve various techniques, including some type of fixation, either rigid or semirigid, with or without bone grafts. ${ }^{1-5}$ We present 6 cases of sternal nonunion after median sternotomy and trauma treated with open reduction and internal fixation with rigid sternal plates. Our technique was successful in relieving the pain and healing the fracture. The equipment and technique is straightforward, and the method is safe. Moreover, biomechanical studies have demonstrated the superiority of rigid fixation over wire fixation. Our series differs from previous reports in that the use of the Sternalock plates requires minimal dissection 


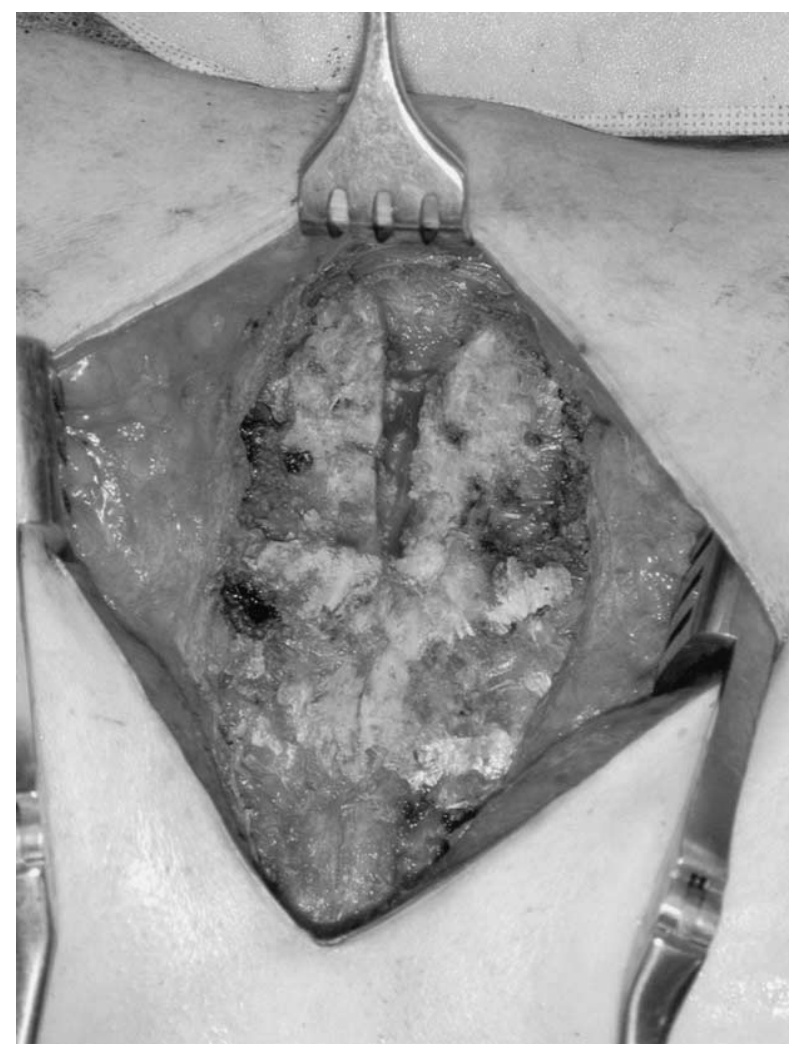

Figure 1. Nonunion of the manubrium.

\section{TABLE 1. Patient diagnosis and demographic}

\begin{tabular}{ccccc}
\hline $\begin{array}{l}\text { Patient } \\
\text { no. }\end{array}$ & Age (y) & Sex & Cause & $\begin{array}{c}\text { Months of sternal } \\
\text { nonunion }\end{array}$ \\
\hline 1 & 66 & M & Median sternotomy & 5 \\
2 & 47 & F & Median sternotomy & 7 \\
3 & 47 & F & Traumatic fracture & 8 \\
4 & 24 & M & Traumatic fracture & 12 \\
5 & 49 & M & Median sternotomy & 15 \\
6 & 66 & M & Median sternotomy & 60 \\
\hline
\end{tabular}

of the periosteal blood supply of the sternum. The dissection does not extend to the lateral edges or undersurface of the sternum. Finally, it does not require bone grafting. The success of this technique is dependent on the proper reduction of the fracture or

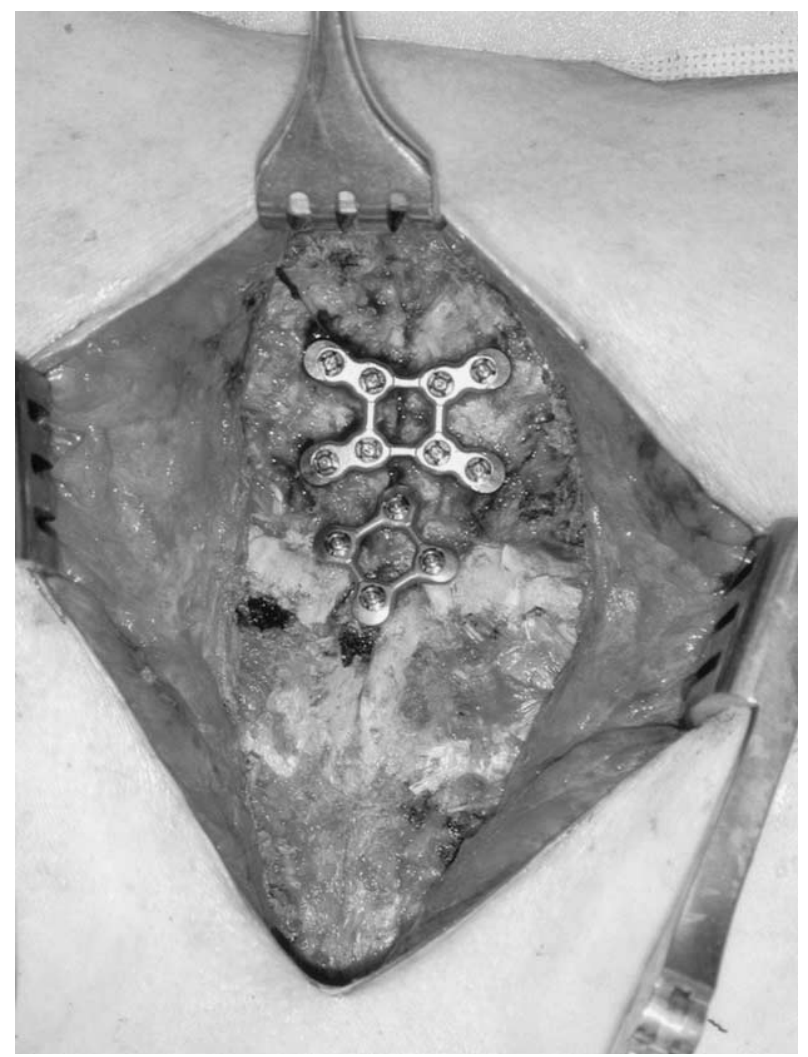

Figure 2. Rigid fixation of the manubrium.

fractures, vascularity of the bony segments, adequate bone stock for purchase of the screws, and absence of infection.

\section{References}

1. Mayba II. Non-union of fractures of the sternum. J Bone Joint Surg Am. 1985;67:1091-3.

2. Coons DA, Pitcher JD, Braxton M, Bickley BT. Sternal nonunion. Orthopedics. 2002;25:89-91.

3. Hendrickson SC, Koger KE, Morea CJ, Aponte RL, Smith PK, Levin LS. Sternal plating for the treatment of sternal nonunion. Ann Thorac Surg. 1997;64:888-9.

4. Eich BS, Heinz TR. Treatment of sternal nonunion with the Dall-Miles cable system. Plast Reconstr Surg. 2000;106:1075-8.

5. Bertin KC, Rice RS, Doty DB, Jones KW. Repair of transverse sternal nonunions using metal plates and autogenous bone graft. Ann Thorac Surg. 2002;73:1661-2. 